\title{
Effects of acetazolamide on cerebral blood flow and brain tissue oxygenation
}

\author{
N.A. Lassen, L. Friberg, J. Kastrup, D. Rizzi and J.J. Jensen \\ Department of Clinical Physiology/Nuclear Medicine, Bispebjerg Hospital, DK-2400 Copenhagen, Denmark.
}

\begin{abstract}
Summary: Oral administration of $1 \mathrm{~g}$ of acetazolamide to 8 normal subjects studied at sea level and in normoxia caused an acute increase in cerebral blood flow (CBF). During the subsequent prolonged oral treatment with $1 \mathrm{~g}$ of acetazolamide daily, CBF returned to normal within 2 days. The alveolar $\mathrm{CO}_{2}$ tension decreased gradually to $\mathbf{7 0} \%$ of the control value, indicating hyperventilation. At sea level hyperventilation will not increase brain oxygenation significantly in normal man, as the arterial oxygen content only increases minimally, while CBF is unchanged. At high altitude the beneficial effects of acetazolamide on the symptoms of acute mountain sickness may well be due to an improved oxygen supply to the brain, as hyperventilation will, at the low ambient $\mathrm{PO}_{2}$, cause a significant increase of the arterial oxygen content, while CBF presumably is unaffected by the drug. During hypoxia at high altitude the overall effect of prolonged acetazolamide treatment may thus be equivalent to a descent by several hundred metres.
\end{abstract}

\section{Introduction}

Acetazolamide has for several years been known to reduce the symptoms of acute mountain sickness, i.e. the cerebral symptoms that many sea-level dwellers experience during the first days or weeks of exposure to high altitude hypoxia. ${ }^{1-4}$ The drug increases ventilation $^{5,6}$ and also causes a considerable increase in cerebral blood flow (CBF) a few minutes after intravenous injection of the drug. ${ }^{7-9}$ Both factors might be of importance for the beneficial effect as both changes would, other factors being equal, tend to augment cerebral oxygen supply. Which one of these two factors is the most important under the conditions of many days of oral acetazolamide taken by mountaineers during acclimatization after abrupt ascent to altitude?

The present study reports sea-level (normoxic) studies of alveolar $\mathrm{PCO}_{2}$ and $\mathrm{CBF}$ during 10 days of oral acetazolamide administration to normal volunteers. This is a baseline study for similar observations at hypoxia.

The intravenous injection of $1 \mathrm{~g}$ of acetazolamide results in a prompt increase in $\mathrm{CBF}$ ? $^{7} \mathrm{CBF}$ measured in conscious human subjects at sea level increased by about $50 \%$ above control values 3 minutes after injection. There was a further rise to about $60 \%$ of the control value after 20 minutes. The cerebral oxygen uptake was not affected. This is important, as it

Correspondence: N.A. Lassen M.D. uptake was not affected. This is important, as it permits the calculation of blood flow as the percentage rise in the reciprocal cerebral arterio-venous oxygen difference. $^{\text {? }}$

The duration of this response is not known, but in view of the fairly rapid elimination of acetazolamide, complete inhibition of carbonic anhydrase cannot be expected to last for long. It is interesting to note, in contrast, that the intravenous injection of $500 \mathrm{mg}$ of acetazolamide increases CBF only insignificantly during the first 5 minutes ${ }^{8}$ with a rise of $30 \%$ being seen later. ${ }^{9}$ This suggests that in order to obtain a sustained increase of $\mathrm{CBF}$, a high dose of oral acetazolamide would be required.

\section{Methods and results}

Preliminary studies with oral administration are now being performed in our laboratory. Cerebral blood flow has been measured in 8 normal subjects in normoxia at sea level by the intravenous xenon-133 injection method. ${ }^{10,11}$ This study showed that a single oral dose of $1 \mathrm{~g}$ of acetazolamide increased CBF (40$50 \%$ ) at 3 hours with only a small decrease in endexpiratory $\mathrm{PCO}_{2}$. The following 10 days, $500 \mathrm{mg}$ acetazolamide was taken twice daily. After 2 days CBF had practically normalized but clear cut hyperventilation was evident with alveolar $\mathrm{PCO}_{2}$ reaching $70 \%$ of normal at 10 days (Figure 1). 


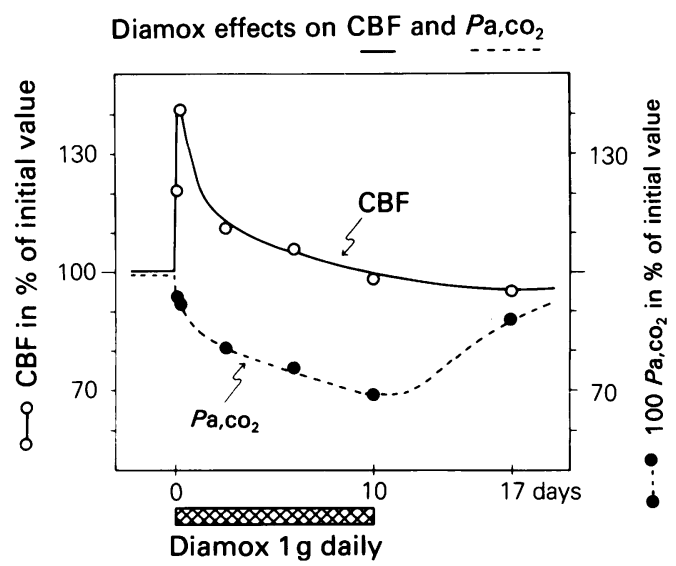

Figure 1 Cerebral blood flow (CBF) and arterial $\mathrm{PCO}_{2}$ $\left(\mathrm{Pa}, \mathrm{CO}_{2}\right)$ during and after acetazolamide administration.

\section{Discussion}

Acetazolamide inhibits carbonic anhydrase both in the erythrocytes and in the cells of the tissues. Blocking the erythrocytes will cause tissue $\mathrm{PCO}_{2}$ to increase relative to arterial $\mathrm{PCO}_{2}$ so that the venous blood can leave the tissue with an increased $\mathrm{PCO}_{2}$, in order for $\mathrm{CO}_{2}$ to be eliminated at its normal rate. Inhibition of tissue carbonic anhydrase may enhance tissue acidosis beyond the level indicated by the tissue $\mathrm{PCO}_{2}$. If, as suggested by Severinghaus \& $\operatorname{Cotev}^{12}$ and by Heuser $e t$ al. ${ }^{13}$ carbonic acid and not $\mathrm{CO}_{2}$ is the end product of metabolism, then carbonic acid must accumulate in order for the uncatalysed reaction to proceed at the same rate as the catalysed reaction.

Both the physiological parameters that we studied are controlled by intracellular $\mathrm{pH}$ at normoxia. Ventilation is controlled by $\mathrm{pH}$ in the brain stem's respiratory centres and cerebral blood flow by the $\mathrm{pH}$ of smooth muscle cells in brain arterioles. The time course of the acetazolamide-induced increases in ventilation and in $\mathrm{CBF}$ were distinctly different. Ventilation was found to increase gradually over the 10 days of medication. The $30 \%$ decrease in alveolar $\mathrm{PCO}_{2}$ at the end of the study corresponds to a $50 \%$ increase in alveolar ventilation. The progressive increase in ventilation suggests a progressive acidosis in the chemosensitive areas of the brain stem. This might be due to slowness of acetazolamide accumulation in the brain, if indeed tissue anhydrases must be inhibited to obtain the full acidotic response. The brain stem has a high rate of metabolism and would therefore require a considerable rise in tissue carbonic $\frac{2}{2}$ acid in order for $\mathrm{CO}_{2}$ to be formed at the same rate asळ normally.

In view of the sustained increase of ventilatory drive the brevity of the CBF increase was a surprise. After a few days CBF returned to its normal level. This suggests that $\mathrm{pH}$ in the arteriolar smooth muscle cells had become normalized also. The gradual reduction in $\frac{\bar{s}}{\bar{T}}$ arterial $\mathrm{PCO}_{2}$ may be important in this respect. It $\stackrel{\mathbb{D}}{\stackrel{D}{\Omega}}$ should be noted that the smooth muscle cells are muches less active metabolically than brain tissue. Thus, inhibition of the local carbonic anhydrase will not. produce nearly as much carbonic acid acidosis in the $\vec{\omega}$ arteriolar wall as in the brain tissue.

The results we obtained at sea level show that in normoxia prolonged acetazolamide administration to 3 . normal man hardly influences brain oxygenation ando CBF is normal despite hyperventilation. The $30 \%$ v decrease in alveolar $\mathrm{PCO}_{2}$ must correspond to a. decrease of arterial $\mathrm{PCO}_{2}$ from 40 to $28 \mathrm{~mm} \mathrm{Hg}$. Hence $-\dot{\mathrm{O}}$ arterial $\mathrm{PO}_{2}$ also rises by about $12 \mathrm{~mm} \mathrm{Hg}$; this wills only increase arterial oxygen content minimallys because of the shallowness of the oxygen saturation curve at these pressures.

In prolonged exposure to hypoxia no data on acetazolamide effects on arterial $\mathrm{PCO}_{2}$ or $\mathrm{CBF}$ are available. But, assuming the same directional changes are superimposed on the hypoxic responses, then $\mathrm{a} v$ considerable effect on brain oxygenation must $\Phi$ predicted because increasing the alveolar $\mathrm{PO}_{2}$ wits augment arterial oxygen content considerably, due to the steepness of the saturation curve at hypoxic $P \mathrm{O}_{0}$ values. The values published by Gill et al. ${ }^{14}$ on alveolar air composition at high altitude imply that, if otherfactors remain equal, then a $50 \%$ increase in ventila $\frac{0}{3}$ tion induced by acetazolamide will correspond to an acute descent by approximately 1000 metres.

Despite reservations on extrapolating to hypoxic. conditions the present study suggests that carbonicanhydrase inhibitors should be commenced severab days before abrupt ascent to altitude; that it should be continued throughout the stay and that a compoun 8 and dose should be used which inhibits the anhydrase in both erythrocytes and brain cells. Much furthero work should be carried out to clarify these and other points. The techniques described are atraumatic ando. could be used in the field. It is important as high mountain climbing and trekking has become so popular; why mar the pleasure with unnecessary 0 discomfort and risk!

\section{Acknowledgement}

We wish to thank Lederle, Div. of American Cyanamideo Company, for their support during this study. 


\section{References}

1. Cain, S.M. \& Dunn, J.E. Low doses of acetazolamide to aid accommodation of men to altitude. J Appl Physiol 1966, 21: 1195-1200.

2. Mani, K.V. \& Weinstein, S.A. Effect of carbonic acid inhibition on blood gas and acid base balance during hypoxia. Bulletin Johns Hopkins' Hospital 1966, 119: 331-342.

3. Evans, W.O., Robinson, S.M., Horstman, D.H., Jackson, R.E. \& Weiskopf, R.B. Amelioration of the symptoms of acute mountain sickness by staging and acetazolamide. Aviat Space Environ Med 1976, 47: 512516.

4. Hackett, P.H., Rennie, D. \& Levine, H.D. The incidence, importance and prophylaxis of acute mountain sickness. Lancet 1976, ii: 1149-1154.

5. Barak, A.J., Beber, M. \& Jacobi, H.P. The effect of acetazolamide (Diamox) on ammonium chloride and acid-base balance in pulmonary emphysema: a comparative study. Am J Med Sci 1957, 234: 71-73.

6. Galdston, M. \& Geller, J. Effects of aminophylline and Diamox alone and together on respiration and acid-base balance and on respiratory response to carbon dioxide in pulmonary emphysema. Am J Med 1957, 23: 183-196.

7. Vorstrup, S., Henriksen, L. \& Paulson, O.B. Effect of acetazolamide on cerebral blood flow and cerèbral metabolism rate for oxygen. J Clin Invest 1984, 74: 16341639.
8. Friis, M.L., Paulson, O.B. \& Hertz, M.M. Carbon dioxide permeability of the blood-brain barrier in man. The effect of acetazolamide. Microvasc Res 1980, 20: 71-80.

9. Gotoh, F., Meyer, J.S. \& Tomita, M. Carbonic anhydrase inhibition and cerebral venous blood gases and ions in man. Arch Intern Med 1966, 117: 39-46.

10. Veall, N. \& Mallett, B.L. The Xe-133 inhalation technique for regional cerebral flow studies. In: Fellinger, $\mathbf{K}$. \& Hoffer, R. (eds) Radioactive Isotope in Klinik und Forschung. Urban and Schwarzenberg, Munchen, 1967, Vol. III, p. 167.

11. Risberg, J., Uzzell, B.P. \& Obrist, W.D. Spectrum subtraction technique for minimizing extracranial influence on cerebral blood flow measurements by 133-xenon inhalation. Stroke 1977, 8: 380-382.

12. Severinghaus, J.W. \& Cotev, S. Carbonic acidosis and cerebral vasodilation after Diamox. Scand J Clin Lab Invest 1968, suppl. 102, $1 \mathrm{E}$.

13. Heuser, D., Astrup, J., Lassen, N.A. \& Betz, E. Brain carbonic acid acidosis after acetazolamide. Acta Physiol Scand 1975, 93: 385-390.

14. Gill, M.B., Milledge, J.S., Pugh, L.G.C.E. \& West, J.B. Alveolar gas composition at 21,000 to 25,700 feet. $J$ Physiol (Lond) 1962, 163: 373-377. 